\title{
Preparing for the Trend of Aging in Place: Identifying Interprofessional Competencies for Integrated Care Professionals
}

\author{
Choi, Eun Jeong ${ }^{1} \cdot$ Park, Myonghwa ${ }^{2}$ \\ ${ }^{1}$ Nurse, Chungnam National University Hospital, Daejeon \\ ${ }^{2}$ Professor, College of Nursing, Chungnam National University, Daejeon, Korea
}

\begin{abstract}
Purpose: The purpose of this study was to identify interprofessional competencies for the integrated community care of older people. Methods: This study used a methodological approach, and the specific process aimed to identify the components of interprofessional competencies for integrated community care using a scoping review and validating the identified competencies with the Delphi method. The scoping review first identified relevant studies through the following electronic databases: PubMed, CINAHL, Embase, and the Cochrane Library. We then selected studies that met the inclusion criteria and analyzed their results to identify a draft version of the competencies. Expert panels validated the list of competencies through two rounds of the Delphi survey. Results: The two rounds of the Delphi survey revealed consensus. Finally, we developed an interprofessional competency for integrated community care comprising 19 interprofessional core competencies, 20 integrated core care competencies for community care administrators, 13 integrated core care competencies for care coordinators, 13 integrated core care competencies for local service providers, and 12 integrated core care competencies for community health leaders. Conclusion: This study can help inform job descriptions, evaluate the relevant professionals' performance, and develop a competency-based curriculum for better practice.
\end{abstract}

Key Words: Delivery of health care, Integrated; Patient-centered Care; Professional competence; Community integration; Community participation

\section{INTRODUCTION}

The world's population is aging rapidly [1]. It is expected that older people could account for 12 percent of the global population in 2030 and 16 percent in 2050 [2]. Most countries are confronted by the challenge of caring for the increasing number of older people, especially because of the increasing demand for care services to address multiple chronic conditions common in older age and the increasing need among older people for assistance with daily activities such as dressing, bathing, and preparing food [3]. However, the majority of older people want to stay at home as long as possible [4]. 'Aging in place' is defined as people who are living in the community with some degree of independence, rather than being admitted to a residential care facility [5]. To successfully realize 'aging in place,' it is essential for health-care pro- fessionals to focus on individual needs, housing environment, and adequate community-based services that support health and well-being [6].

Despite the increasing numbers of people with complex health and social care needs, healthcare delivery has traditionally focused on caring for illness, rather than caring for the people themselves [7]. To cope with older people's individual complex care needs, integrated healthand social-care services are considered crucial $[8,9]$, and when health and social care professionals collaborate in this endeavor, integrated person-centered care becomes achievable [10]. How then, can we facilitate such collaboration? Caregivers are required to be skilled in working with other professionals [11] as well as appropriately meeting the comprehensive needs of older people [12]. Such interprofessional competencies for the integrated care of older people may help address their burgeoning

\footnotetext{
Corresponding author: Park, Myonghwa https://orcid.org/0000-0002-0329-0010

College of Nursing, Chungnam National University, 266 Munhwa-ro, Jung-gu, Daejeon 35015, Korea.

Tel: +82-42-580-8328, Fax: +82-42-580-8309, E-mail: mhpark@cnu.ac.kr
}

Received: Jul 15, 2021 / Revised: Aug 9, 2021 / Accepted: Aug 17, 2021

This is an open access article distributed under the terms of the Creative Commons Attribution Non-Commercial License (http://creativecommons.org/licenses/ by-nc/3.0), which permits unrestricted non-commercial use, distribution, and reproduction in any medium, provided the original work is properly cited. 
needs by providing quality services.

Previous attempts to identify integrated care competencies for caregivers of older people have been restricted to the generic competency components of interprofessional care, or have focused mainly on the aspects of care coordination of integrated care $[13,14]$. However, as integrated care is provided at multiple levels such as at the system, service, and personal levels [15], professionals who work at each level may take on distinctive roles. Thus, interprofessional competencies for the integrated care of older people should be more specifically defined based on the roles of relevant core professionals to promote quality care for older people.

The purpose of this study is to identify interprofessional competencies for professionals who provide integrated community care for older people. The specific aims of this study are:

- To identify the initial components of interprofessional competencies for the integrated community care of older people

- To validate the identified interprofessional competencies

\section{METHODS}

\section{Design}

This study is a methodological research to identify interprofessional competencies for the integrated community care for older people.

\section{Phase and Strategy}

The study includes two phases of work. In the first phase, a scoping review [16] is used to identify the initial components of interprofessional competencies from current international sources. In the second phase, the paper uses the modified Delphi method [17] to validate the competencies from expert consensus. The method uses a chain of rounds and starts with a questionnaire or an interview to solicit the recruited experts' opinion and comments related to aspects of the study's investigation [17]. Finally, the interprofessional competencies are identified (Figure 1).

\section{1) Phase 1. Generating the initial version of interprofessional} competencies

(1) Search strategies

Journal articles, books, and reports based on the inclusion criteria were collected from four databases: PubMed, CINAHL, Embase, and Cochrane Library. The keywords
Identifying the initial components of competencies using scoping review

Content analysis based on identified competencies

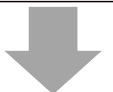

$<$ Delphi Round 1 $>$

Conducting the first round of the Delphi survey using the initial version of competencies

Modifying competencies based on the feedbacks from the first round of Delphi

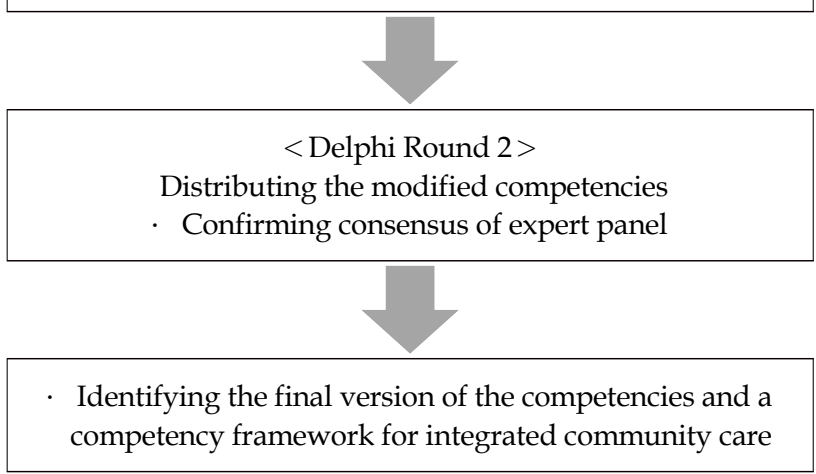

Figure 1. The phase and strategy of this study.

search strategy was employed using all terminological variants of ("integrated care" OR "collaborative care" OR "health and social care" OR "interprofessional care" OR "interdisciplinary care" OR "multidisciplinary care" OR "multiprofessional care") OR "Delivery of Health Care, Integrated" complying with MeSH (Medical Subject Headings) terms AND "Competence".

\section{(1) Eligibility criteria}

The study included reviews of journal articles, reports, and grey literature published from 1990 through 2020. This review did not define the evidence of certain interventions, so the study design and quality were not limited. Literature written in Korean and English was included.

(2) Inclusion criteria

- The competencies described are scoped mainly to the workforce

- The competencies that are defined, referred, evaluated, or compared relate to integrated care 
- The workforce that is referred to is relevant to health and social care in the community

(3) Exclusion criteria

- Competencies that referred only to caring for specific patient groups or focused on a clinical care setting were not considered for this review

After removing duplicate studies, we selected studies based on titles and abstracts and finally, reviewed full text studies that met the inclusion criteria.

(2) Data extraction and synthesis

If the literature met the inclusion criteria, data relevant to interprofessional competencies for the integrated community care of older people were extracted. The extracted data from the reviewed literature were included in data extraction records and synthesized in data-summary charting form. Key information, such as authorship, article type, country, and list of competencies were included in Table 1 . Then, the information organized in charting form was collated and reported from the literature's descriptions of interprofessional competencies for the integrated community care of older people. The competencies were finally analyzed using content analysis [27] Two researchers independently analyzed the competencies to identify different concepts and categorized the contents. Then, the two researchers compared all the categorized competencies and made changes. They verified the contents and wording of the competencies to reach consensus. Finally, the drafted version of competencies was identified.

\section{2) Phase 2. Experts identify the validity of the competencies}

(1) Expert group

For the two rounds of the Delphi survey, experts were recruited from the health and social care fields to form an expert panel. The panel included professors or professionals experienced in researching the field of caring for older people, or who had delivered care to older people within the community. Purposive sampling was used to recruit participants for the study. To produce a comprehensive list of experts, conference proceedings and articles published in the journal related to health and social care were reviewed to identify the authors, and the organizations and institutes related to health care and social services in the community were asked to recommend appropriate experts. The professors and researchers were selected based on their strong records of publications and presentations related to integrated care for older people in the community. The selected practitioners were working in institutes providing health care and social services in the community and had at least 3 years of working experience. An email invitation was sent to each candidate of expert panel. Finally, ten experts participated in the Delphi survey (Table 2) (Delphi typically recommends the participation of ten to 15 participants) [28].

\section{(2) Procedures and analysis}

The purpose of the Delphi was to reach consensus on each component of the core and job-specific interprofessional competencies for the integrated community care of older people. To establish validity, researchers and professionals with research or working experience in the area of integrated care in the community conducted a pilot test to review the initial list of competencies and complete the Delphi survey. After the pilot test, minor revisions were made to the statements in the questionnaire to facilitate the potential respondents' understanding of the meaning of the sentences. The final version of the questionnaire was distributed and collected by e-mail. The responses to the questionnaire in each round remained anonymous to inspire the participants to actively rate the questionnaire. The questionnaires were given to the participants at two time points and were subsequently collected. In each round, the participants were given two weeks to complete the questionnaire. The second questionnaire was drawn up based on the reviewed data from the previous round.

\section{Round 1}

A survey questionnaire was distributed to all participants, and their responses were rated on a 5-point Likerttype scale ranging from 1 (strongly disagree) to 5 (strongly agree). The questions related to each component of the interprofessional competencies required for the integrated community care of older people. All participants were also asked to explain their rating and to recommend new components of competencies if they felt the need to do so.

\section{Round 2}

Based on the experts' opinions, statements of competencies that were incongruent with the aim of the study or perceived to be duplicates were deleted before Round 2 was conducted. A brief summary of the modifications made based on the experts' comments and the questionnaire, including the revised components of competencies, were then distributed to the expert panel. The feedback from Round 1 was presented as the mean and SD scores of all the experts on the panel. The participants 
Table 1. Literatures Identified in the Scoping Review

\begin{tabular}{|c|c|c|}
\hline Author, year & Study location & Summarized core competencies \\
\hline Harrison \& Lydon, 2008 [18] & England & $\begin{array}{l}\text { - Assessment, promoting health, and preventing health conditions } \\
\text { - } \text { Managing long-term conditions } \\
\text {. } \text { Pare coordination } \\
\text {. } \text { Caring in the home and community and supporting self-care }\end{array}$ \\
\hline $\begin{array}{l}\text { Jones, Bhanbhro, Grant, \& Hood, } \\
2013 \text { [19] }\end{array}$ & England & $\begin{array}{l}\text { - } \text { Considering autonomy and culture } \\
\text { - Assessment and health promotion } \\
\text { - Close relationship and collaboration } \\
\text { - Work on health and social environment } \\
\text { - } \text { Motivating patients } \\
\text { - } \text { Community-based services arrangement }\end{array}$ \\
\hline Covert et al., 2019 [20] & USA & $\begin{array}{l}\text { - Assessment and disease prevention and management } \\
\text {. Community health and professional practice } \\
\text {. Communication } \\
\text {. Diversity and inclusion }\end{array}$ \\
\hline Kallio et al., 2020 [21] & Finland & $\begin{array}{l}\text { Promoting health and social-related well-being } \\
\text { - Dealing with information technology and records } \\
\text {. } \text { Multiculturalism } \\
\text { Educating about health and social care }\end{array}$ \\
\hline Tabbush, 2012 [22] & USA & $\begin{array}{l}\text { Planning and promoting services } \\
\text { - Delivering the services profitably and successfully } \\
\text {. Evaluating the services }\end{array}$ \\
\hline $\begin{array}{l}\text { Maryland Department of Health, } \\
2019 \text { [23] }\end{array}$ & USA & $\begin{array}{l}\text { - } \text { Ability to build and support community } \\
\text { - Communication } \\
\text { - } \text { Understanding local resources and system } \\
\text { - } \text { Care coordination } \\
\text { - Instruction skills for health behavior changes }\end{array}$ \\
\hline South, Raine, \& White, 2010 [24] & England & $\begin{array}{l}\text { - Community involvement } \\
\text { - Training relevant workers } \\
\text { - Opportunity for management and support } \\
\text { - Supporting suitable resources }\end{array}$ \\
\hline $\begin{array}{l}\text { NHS England \& NHS Improvement, } \\
2020 \text { [25] }\end{array}$ & England & $\begin{array}{l}\text { - Comprehensive leadership and responsibility } \\
\text { - Planning and managing human resources } \\
\text { - Dealing with patients' outcomes and experience } \\
\text { - Information technology } \\
\text { - Training and practical supervision } \\
\text { - Research and development and service improvement } \\
\text { - Collaboration }\end{array}$ \\
\hline $\begin{array}{l}\text { Health Education England, } \\
2016 \text { [13] }\end{array}$ & England & $\begin{array}{l}\text { - } \text { Communication } \\
\text { - } \text { Forming and maintaining partnership } \\
\text {. Practical knowledge and expertise } \\
\text { - Personal advancement and training } \\
\text { - } \text { Managing data and information }\end{array}$ \\
\hline $\begin{array}{l}\text { Nummela, Juujärvi, \& Sinervo, } \\
2019 \text { [26] }\end{array}$ & Finland & $\begin{array}{l}\text { Providing guidance to clients } \\
\text { - Responsibility for people's well-being } \\
\text {. Approach to the services with proficiency and accuracy }\end{array}$ \\
\hline
\end{tabular}


Table 2. The Characteristics of Expert Panel

\begin{tabular}{|c|c|c|c|c|}
\hline Expert & Profession & Discipline & Degree & Research or working experience \\
\hline 1 & Professor & Medicine & Ph.D. & Preventive medicine \\
\hline 2 & Professor & Nursing & Ph.D. & Community nursing \\
\hline 3 & Professor & Nursing/Public health & Ph.D. & Geriatric nursing/Integrated care \\
\hline 4 & Professor & Public health & Ph.D. & Geriatric health care \\
\hline 5 & Professor & Social work & Ph.D. & Integrated care \\
\hline 6 & Researcher & Nursing & Ph.D. & Health care policy \\
\hline 7 & Researcher & Social work & Ph.D. & Long-term care \\
\hline 8 & Practitioner & Medicine & M.D. & Primary care physician \\
\hline 9 & Practitioner & Social work & M.S. & Medical social work \\
\hline 10 & Practitioner & Health administration & M.S. & Administration \\
\hline
\end{tabular}

were given the initially checked score of each statement and asked to reconsider their initial decisions about ambiguous statements made from Round 1 and express their agreement with the new statements.

After completing all rounds of the Delphi, the data were analyzed with SPSS (Statistical Package for the Social Scientists) software version 22.0 for Windows (IBM Corp., New York, NY, USA). The content validity index (CVI) was used to calculate content validity [29]. This study used the content validity index for items (I-CVI), and the overall scale (S-CVI) to calculate the S-CVI/Ave. It followed the standards recommended by Lynn (1986) [29] (with six to 10 experts, the minimum score of I-CVI $=.78$, and the $\mathrm{S}-\mathrm{CVI} / \mathrm{Ave}=.90$ or higher).

\section{Ethical Consideration}

This study was approved by the institutional review board of Chungnam National University (Approval no. 202009-SB-121-01).

\section{RESULTS}

\section{Generating the Initial Competencies}

The primary search returned 95 documents, 10 of which met the inclusion criteria and were reviewed (Figure 2). Five were British-based documents, three were USA based, and two were Finland based. After conducting content analysis of the interprofessional competencies relating specifically to the care of older people extracted from 10 records, 77 subcategories were identified and became a set of competencies. The 77 subcategories were grouped into five categories based on each professional's role and work within integrated care (Figure 3 ).

\section{Establishing Validity through Expert Consensus}

A total of ten experts completed the Delphi survey, and after two rounds, consensus was reached on the components of the competencies. The survey was conducted anonymously; anyone who participated in the survey could not be distinguished from the other participants to ensure reliability of the responses.

In the first round, the expert panel reached a consensus level of 0.8 for 19 out of 21 interprofessional core competencies for the integrated care of older people; the two competencies on which there was not consensus were deleted. The panel did not suggest any new competencies, but minor revisions were made to four competencies based on the expert panel's recommendations. Of the initial 20 integrated care core competencies for community care administrators, 18 items reached the consensus level, and two competencies on which the experts did not reach consensus were deleted. The panel revised one competency and proposed one new competency: planning finance, budgeting and business, and monitoring the cost-effectiveness of the use of finance and resources. Of the initial 12 integrated care core competencies for care coordinators, all competencies reached the consensus level. The expert panel suggested one new competency: improving the work process based on integrated care performance results. Of the 18 initial integrated care core competencies for local service providers, 11 competencies reached the consensus level and seven competencies were deleted. The expert panel suggested two new competencies: sharing resources and information with relevant organizations to benefit community residents and helping community residents confront emergency situations/crises. Of the 11 initial integrated care core competencies for community health leaders, all 


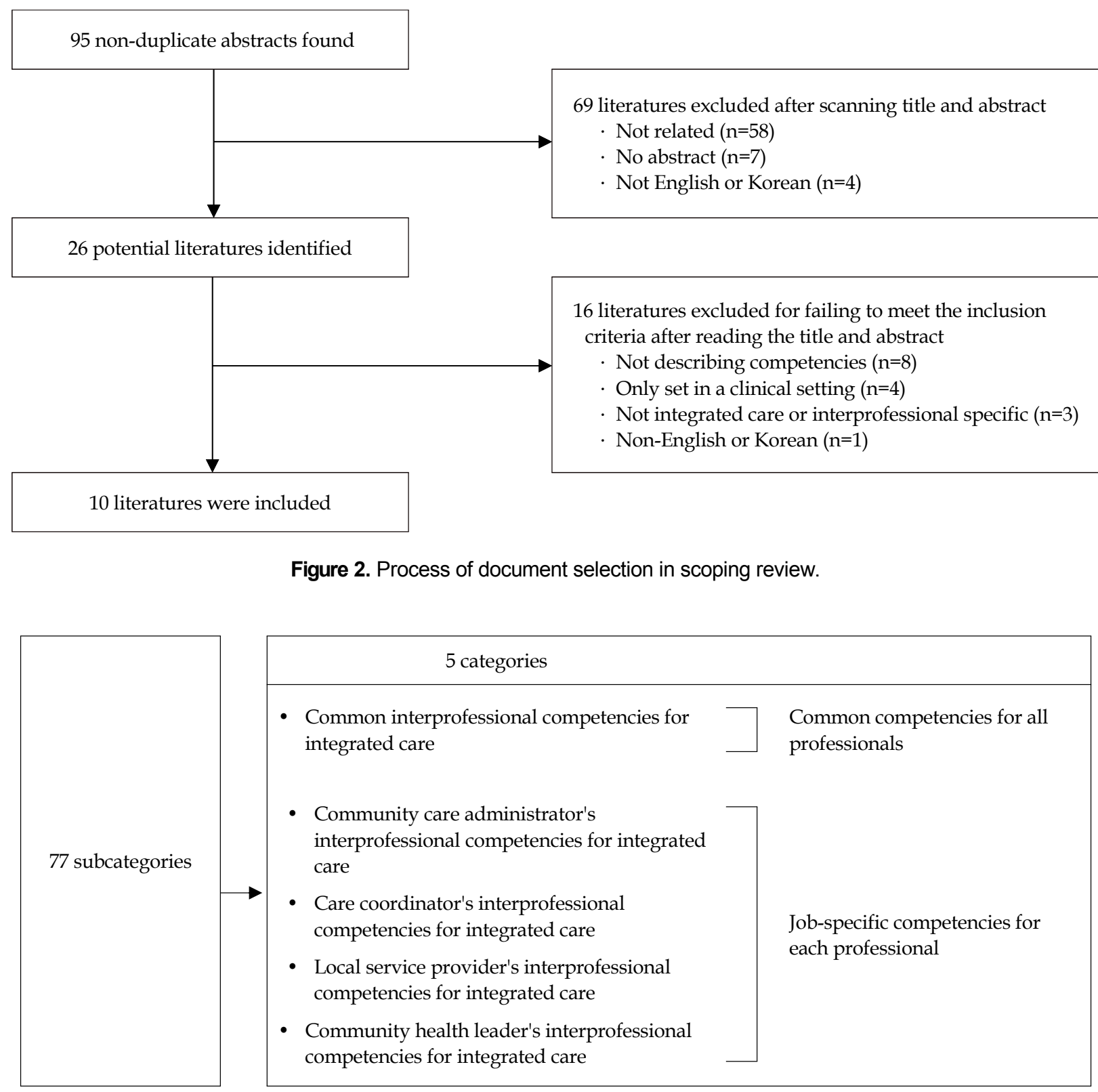

Figure 3. The results of content analysis based on the scoping review.

competencies reached the consensus level. One additional competency was suggested and modification of some competencies was suggested before Round 2 .

In the second round, a high level of support was attained for all modified and additional competencies (The I-CVI for interprofessional competencies for the integrated community care of older people ranged from 0.9 to 1.0, and the S-CVI/Ave was 1.0). Therefore, consensus on all interprofessional competencies was reached.

Five parts of interprofessional competencies for the integrated community care of older people, including the 77 competencies, were identified (Table 3). The first part presents the common interprofessional competencies for the integrated community care of older people, which are 19 common competencies for all integrated care professionals. The last four parts present the interprofessional competencies for each professional relevant to the care for older people in the community: 20 competencies for community care administrators, 13 competencies for care coordinators, 13 competencies for local service providers, and 12 competencies for community health leaders. Finally, based on the identified competencies, a set of interprofessional competencies was identified for integrated community care (Table 4 ). 
Table 3. The Result of Delphi

\begin{tabular}{|c|c|c|c|c|c|}
\hline \multirow{2}{*}{$\begin{array}{l}\text { Category of the } \\
\text { competency }\end{array}$} & \multicolumn{2}{|c|}{ Round 1} & \multicolumn{2}{|c|}{ Round 2} & \multirow{2}{*}{ Description } \\
\hline & $\mathrm{M} \pm \mathrm{SD}$ & $\mathrm{I}-\mathrm{CVI}$ & $\mathrm{M} \pm \mathrm{SD}$ & $\mathrm{I}-\mathrm{CVI}$ & \\
\hline Common competency & $4.43 \pm 0.29$ & 1.0 & $4.58 \pm 0.17$ & 1.0 & $\begin{array}{l}\text { - } 4 \text { common interprofessional } \\
\text { competencies were revised } \\
2 \text { common interprofessional } \\
\text { competencies were deleted and } \\
\text { moved to community care } \\
\text { administrators' competency }\end{array}$ \\
\hline $\begin{array}{l}\text { Administrator's } \\
\text { competency }\end{array}$ & $4.64 \pm 0.27$ & 1.0 & $4.72 \pm 0.15$ & 1.0 & $\begin{array}{l}\text { - } 1 \text { community care administrator's } \\
\text { interprofessional competency } \\
\text { was revised } \\
\text { - } 2 \text { community care administrator's } \\
\text { interprofessional competencies } \\
\text { were deleted } \\
\text { - } 1 \text { community care administrator's } \\
\text { interprofessional competency } \\
\text { was added }\end{array}$ \\
\hline $\begin{array}{l}\text { Care coordinator's } \\
\text { competency }\end{array}$ & $4.80 \pm 0.10$ & 1.0 & $4.78 \pm 0.11$ & 1.0 & $\begin{array}{l}\text { - } 1 \text { care coordinator's competency } \\
\text { was added }\end{array}$ \\
\hline $\begin{array}{l}\text { Local service provider's } \\
\text { competency }\end{array}$ & $4.47 \pm 0.41$ & 0.9 & $4.78 \pm 0.13$ & 1.0 & $\begin{array}{l}\text { - } 2 \text { local service provider's } \\
\text { interprofessional competencies } \\
\text { was added } \\
\text { - } 2 \text { local service provider's } \\
\text { interprofessional competencies } \\
\text { was deleted }\end{array}$ \\
\hline $\begin{array}{l}\text { Community health } \\
\text { leader's competency }\end{array}$ & $4.53 \pm 0.33$ & 0.9 & $4.68 \pm 0.22$ & 1.0 & $\begin{array}{l}\text { - } 5 \text { community health leader's } \\
\text { interprofessional competencies } \\
\text { was revised } \\
\text { - } 1 \text { community health leader's } \\
\text { interprofessional competency } \\
\text { was added }\end{array}$ \\
\hline
\end{tabular}

$\mathrm{M}=$ Mean; $\mathrm{SD}=$ Standard deviation.

\section{DISCUSSION}

This study aimed to extract a set of interprofessional competencies for the integrated community care of older people based on the results of a scoping review and validation through a Delphi survey. Seventy-seven competencies across five parts were identified to promote an integrated approach to the care for older people. This was the first attempt to provide a set of interprofessional competencies for the integrated community care for older people, which includes both the common and job-specific competencies of integrated care professionals and extends the range of included professionals (a local health provider and community health leader, who played a leading role). In addition, the identification of interprofessional competencies for integrated care can serve as the basis for much future work on competency-based practice. For example, the competency framework can serve as a guide to how the defined competencies can be applied in different work settings and help identify the roles of each professional [29]. This competency framework can be useful for standardizing terminology to explain a range of practices and design relevant training [20].

Previous studies identifying interprofessional competency frameworks have often described the general components of interprofessional care, such as teamwork, leadership, and communication skills [14,31]. However, to present a clear direction for professionals, more specific competencies that can lead to appropriate action for older people are required. In addition, previously identified competencies relevant to integrated care in the community have often focused on the characteristics of care coordination $[13,20,25]$. Specific collaboration among professionals in health and social care is important to ensure optimally integrated care practice [32] and that integrated care is implemented at the system, service, and personal levels [15]. This indicates that integrated care professionals would be required to collaborate in multiple situations and work at different levels. In this respect, their competencies need to be specifically defined and they must be able to apply these competencies in their work. Therefore, to design the competency framework, the job- 
Par 1. Common interprofessional competencies for integrated care

- Understanding the definition and concepts of integrated care

- Understanding timely conditions and policies relevant to integrated care

- Understanding the difference between traditional health care policy and integrated care policy

- Understanding person-centered integrated care

- Working collaboratively across integrated care settings to improve professionals' and community residents' experience of care

- Effectively communicating with community residents and other professionals

- Demonstrating inclusive leadership and professional accountability

- Shared decision making with community residents

- Diagnosing health and social problems and finding solutions based on community residents' needs

- Building relationships or networking with community residents and other professionals

- Effectively communicating community residents' needs within a multidisciplinary team

- Understanding the social value of integrated care contributing to the community

- Establishing community resident-centered integrated health and social-care delivery system

- Sharing information related to integrated care with other professionals and community residents

- Collaboratively working with multidisciplinary professionals

- Using ICT (Information and Communication Technology) appropriately for integrated care

- Cooperating or participating in research relevant to integrated care

- Improving public perceptions of integrated care professionals

- Motivating community residents to participate in the process of integrated care

Part 2. Community care administrator's interprofessional competencies for integrated care

- Identifying high-priority needs related to healthcare and social welfare in the community

- Identifying healthcare and social welfare-related problems in the community

- Developing policies relevant to integrated care based on circumstances and problems in the community

- Selecting potential recipients of integrated care services based on community diagnosis

- Planning integrated care strategies locally

- Implementing integrated care planning

- Investing in and securing local resources for living in place in the community

- Building effective working relationships with other professionals working in public/private institutions

- Effectively chairing or leading multidisciplinary team meetings

- Motivating community residents to organize community gatherings to achieve the goals of integrated care

- Finding solutions based on the ideas and opinions of community residents

- Coordinating individuals within multidisciplinary teams to sustain clarity of roles and accountability

- Ensuring a cooperative environment for multidisciplinary team members

- Contributing to the delivery of supervision of other integrated care professionals

- Educating other staff and colleagues based on their competence

- Considering the voice of the community, speaking with one member acting as a representative

- Establishing appropriate local systems for ensuring high quality of care delivery system

- Distributing local resources effectively based on clients' needs

- Planning finance, budget, and business and monitoring cost-effectiveness of the use of finance and resources

- Evaluating the project results related to integrated care to shape ongoing improvement

Part 3. Care coordinator's interprofessional competencies for integrated care

- Discovering community residents who might need integrated care from information linkage system

- Identifying community residents who might benefit from integrated care services based on initial assessment

- Assessing comprehensive health and social needs of community residents

- Determining the patients' comprehensive needs accurately

- Contributing to developing care plans to meet individuals' health and social care needs

- Referring community residents to multidisciplinary meetings to make care plans

- Referring community residents with health care and social welfare needs to adequate services

- Identifying community residents' satisfaction with received services

- Monitoring the quality of services to meet the quality standards and requirements

- Modifying established care plans, implementing continued care management based on the community residents' situation

- Cooperating with community-based organizations and local institutions for integrated care

- Instructing community residents with long-term conditions on how to care for themselves

- Improving the work process based on integrated care performance results 
Table 4. The Interprofessional Competencies for Integrated Community Care (Continued)

Part 4. Local service provider's interprofessional competencies for integrated care

Identifying health and social care needs of community residents to provide person-centered services

Planning local services based on the needs of community residents

- Promoting local services effectively

Developing cooperative relationship with integrated care-related stakeholders (e.g., professionals, community residents)

- Sharing resources and information with relevant organizations to benefit community residents

- Evaluating the community residents' experiences and changes after receiving services

- Improving and designing new local services

- Undertaking training and development of the workforce providing services

Helping the client confront emergencies/crises

- Identifying and prioritizing community residents' complex health and social care needs and arranging adequate services based on he types of clients (e.g., older people, disabled people, women, children, the mentally ill)

Educating and monitoring community residents while practicing self-care

- Identifying the primary community residents' health and social care needs and providing appropriate service

- Consulting with community residents to keep them motivated

Part 5. Community health leader's interprofessional competencies for integrated care

- Identifying health- and social-care related problems of community residents

- Identifying the causes of health- and social-related problems of community residents

- Searching for health- and social-related information and services

- Understanding the importance of participating in the integrated care process

- Encouraging other community residents to participate in community activities, including community gatherings

- Constructing community-leading organizations on integrated care

- Participating in decision making relevant to health- and social-care needs

- Playing a leading role when designing health- and social-related business plans for community residents

- Cooperating with community-based organizations/institutions for integrated care

- Developing self-help groups and actively participating in their meetings

- Participating in evaluating performance results of integrated care and suggesting improvements

- Contributing to, and participating in, research relevant to integrated care

specific competencies of each professional were considered, except for overlapping components shared by all professionals. Each component of competencies was described in as much detail as possible.

The common component of competencies all professionals needed was the fundamental knowledge and skills required for better collaboration, such as interprofessional practice, the nature of integrated care and communication, and teamwork. This result is mostly consistent with the results reported in previous studies [20,31]. Those competencies are relatively general and essential components for all professionals to work interprofessionally among older people. The competencies include key elements for collaboration. When crafting a fundamental training course for all integrated care professionals, these competencies could be considered as evidence.

The identified integrated care core competencies for community care administrators were: establishing policies, improving the community environment, reflecting the health and social care needs of the community, and supporting the general process of integrated care practice. This result aligns well with the characteristics of the system-level implementation of integrated care, which focuses mainly on strengthening system governance and accountability systems [15]. One previous study also re- ported that administrators support interprofessional practice, and that they consider the strategies, structures, and cultures related to their interprofessional works [33]. The findings indicate that identifying integrated care core competencies for community care administrators would contribute to constructing an administrative foundation for integrated care, considering the relevant workforce and financial management.

The identified integrated care core competencies for care coordinators focus mainly on inspiring community residents to participate in health- and social-related activities and connecting them to community-based care services $[13,34]$. This result is similar to the competencies identified in previous studies. The core competencies of 'care navigators' are to support individuals' ability to conduct health-promoting activities [35] and establish increasing partnership between a person and a relevant provider [36]. 'Link workers' are also competent for assessing comprehensive care needs and connecting people to accessible services [34]. This finding presents that to effectively develop care workers' competencies, a practicum-based curriculum would be significant because these competencies are required to be continuously interactive with clients in practice.

The identified integrated care core competencies for 
local service providers are: developing new and quality health- and social-care services and delivering local services based on clients' complex needs. Community-based organizations are required to possess leadership and management skills [22] as well as provide appropriate direct health- and social-care services (e.g., rehabilitative exercises, nutrition consultation, chronic disease management) $[37,38]$. The findings indicate that when developing local service providers' integrated care core competencies, training needs to focus on strategies that identify the comprehensive unmet needs of individuals and improve service quality and the delivery process, based on the clients' satisfaction.

The identified integrated care core competencies for community health leaders focus mainly on leaders playing a meaningful role as proactive members of the community by being involved in decision-making relevant to the integrated care system and encouraging other resident peers to participate in community-based health and social activities to enhance the well-being of the older people. Previous studies similarly have reported that leadership roles should include active participation in decisions related to policies that are important to their community. Such studies also concur on the suggestion that leaders and other stakeholders should proactively develop a health-promoting culture in the community and engage in local community affairs [24,39]. Person-centered integrated care needs community residents' involvement in the process of integrated care, and these residents must be considered partners. In addition, those community members living in close proximity to other community members who need help with well-being-related issues could empower other community residents to become involved in health-promotion activities as well as helping them overcome the community's healthand social-related problems [24,39]. Community health leaders could be both proactive participants and frontline workers who can reach their community nearby and be familiar with community members. In this aspect, community health leaders should be deemed an essential component of integrated care because it could be a significant trigger for successful community residents' involvement in the process of integrated care. To help community health leaders seize opportunities to become equipped with the appropriate competencies, structured education training in fundamental knowledge of health and well-being should be actively promoted. This would ensure that individuals understand their roles and capitalize on interprofessional learning opportunities [40].
We propose several directions for future studies. First, the focus of this study is to identify interprofessional competencies for integrated care for relevant professionals. This study defines and presents a list of comprehensive interprofessional competencies for integrated care to help each professional become competent in their work. However, to better prepare professionals and enable them to meet the complex needs of older adults, further studies need to explore ways to develop the interprofessional competencies of relevant professionals using effective training and competency-based education programs. In addition, the factors that prevent professionals from applying their competencies in terms of upgrading policies and systems should be identified and eliminated so competent professionals can achieve comprehensive interprofessional care.

\section{Limitations}

This study was conducted in Korea to identify competencies for integrated care in the community. In order to apply this competency internationally, some statements relating to the required competencies may need minor adjustments based on the context of each country because each country has different policies, health-care delivery systems, and cultural characteristics.

\section{CONCLUSION}

The research and literature used in this study focused on identifying interprofessional competencies for an integrated care framework that incorporates health care and social services. With this knowledge and the appropriate attitude and skills, integrated care professionals will be better prepared to provide leadership in working with the complex needs of community residents and collaborate with multidisciplinary workforces. The competencies can be used to inform job descriptions, enlist planning professionals, and evaluate them to identify who can provide integrated care in a community setting in terms of applying the appropriate knowledge and skills that will lead to the enhancement of integrated care that addresses the health and social care needs of older people in the community. Such enhancement will help these older members of the community age in a place where they want to stay with independence and dignity for the rest of their lives.

\section{CONFLICTS OF INTEREST}

The authors declared no conflict of interest. 


\section{AUTHORSHIP}

Study conception - CEJ and PM; Design acquisition - CEJ; Data collection - CEJ and PM; Analysis and interpretation of the data CEJ and PM; Drafting and critical revision of the manuscript CEJ; Final approval - CEJ and PM.

\section{ACKNOWLEDGEMENT}

This paper is based on first author's dissertation for the degree of doctor of philosophy in Nursing.

\section{REFERENCES}

1. Beard JR, Officer A, de Carvalho IA, Sadana R, Pot AM, Michel $\mathrm{JP}$, et al. The world report on ageing and health: a policy framework for healthy ageing. Lancet. 2016;387(10033):2145-54. https://doi.org/10.1016/S0140-6736(15)00516-4

2. United Nations. World population prospects 2019: Highlights. New York: United Nations; 2019. 392 p.

3. Goodwin N, Dixon A, Anderson G, Wodchis W. Providing integrated care for older people with complex needs: lessons from seven international case studies. London: The King's Fund 2014; 2014. 28 p.

4. Information Resources Management Association. User-driven healthcare: concepts, methodologies, tools, and applications. Hersey, PA: Medical Information Science Reference; 2013. Chapeter28, User diversity as a challenge for the integration of medical technology into future smart home environments; p. 553-83.

5. Davey J, Nana G, de Joux V, Arcus M. Accommodation options for older people in Aotearoa/New Zealand [Internet]. Christchurch: Centre for housing research; 2004 Jan [cited 2020 Jan 19]. Available from:

https://thehub.swa.govt.nz/resources/accommodation-opti ons-for-older-people-in-aotearoanew-zealand/

6. Bigonnesse $\mathrm{C}$, Chaudhury $\mathrm{H}$. The landscape of aging in place in gerontology literature: emergence, theoretical perspectives, and influencing factors. Journal of Aging and Environment. 2020;34(3):233-51. https://doi.org/10.1080/02763893.2019.1638875

7. Harvey G, Dollard J, Marshall A, Mittinty MM. Achieving integrated care for older people: shuffling the deckchairs or making the system watertight for the future?. International Journal of Health Policy and Management. 2018;7(4):290-3. https://doi.org/10.15171/ijhpm.2017.144

8. Goodwin N. Understanding integrated care. International Journal of Integrated Care. 2016;16(4):1-4. https://doi.org/10.5334/ijic.2530

9. Vrijhoef H, Thorlby R. Developing care for a changing population: supporting patients with costly, complex needs [Internet] London: Nuffield Trust; 2016 May [updated 2016 May 13; cited 2021 Feb 13]. Available from:

https://www.nuffieldtrust.org.uk/research/developing-care -for-a-changing-population-supporting-patients-with-costlycomplex-needs

10. World Health Organization. Integrated care models: an overview [Internet]. Copenhagen: World Health Organization regional office for Europe; 2016 Oct [cited 2020 Jul 10]. Available from: https://www.euro.who.int/en/health-topics/Health-syste $\mathrm{ms} /$ health-services-delivery/publications/2016/integratedcare-models-an-overview-2016

11. Gilles I, Filliettaz SS, Berchtold P, Peytremann-Bridevaux I. Financial barriers decrease benefits of interprofessional collaboration within integrated care programs: results of a nationwide survey. International Journal of Integrated Care. 2020; 20(1):1-9. https://doi.org/10.5334/ijic.4649

12. Herr M, Arvieu JJ, Aegerter P, Robine JM, Ankri J. Unmet health care needs of older people: prevalence and predictors in a French cross-sectional survey. The European Journal of Public Health. 2014;24(5):808-13. https://doi.org/10.1093/eurpub/ckt179

13. Health Education England. Care navigation: a competency framework [Internet]. London: Health Education England 2016; 2016 [cited 2020 Jul 10]. Available from: https://www.hee.nhs.uk/our-work/care-navigation

14. Wood V, Flavell A, Vanstolk D, Bainbridge L, Nasmith L. The road to collaboration: developing an interprofessional competency framework. Journal of Interprofessional Care. 2009;23 (6):621-9. https://doi.org/10.3109/13561820903051477

15. World Health Organization. Integrated care for older people (ICOPE) implementation framework: guidance for systems and services. Geneva: World Health Organization; 2019. 42 p.

16. Arksey H, O'Malley L. Scoping studies: towards a methodological framework. International Journal of Social Research Methodology. 2005;8(1):19-32. https://doi.org/10.1080/1364557032000119616

17. Keeney S, McKenna H, Hasson F. The Delphi technique in nursing and health research. Hoboken, NJ: Wiley-Blackwell; 2011. 208 p.

18. Harryson S, Lydon J. Health visiting and community matrons: progress in partnership. Community Practitioner. 2008;81(2): 20-3. Available from:

https://link.gale.com/apps/doc/A176368719/AONE?u=an on 2 b0 bc7c4\&sid=googleScholar\&xid $=43 \mathrm{ffd} 877$

19. Jones R, Bhanbhro SM, Grant R, Hood R. The definition and deployment of differential core professional competencies. Health and Social Care in the Community. 2013;21(1):47-58. https://doi.org/10.1111/j.1365-2524.2012.01086.x

20. Covert H, Sherman M, Miner K, Lichtveld M. Core competencies and a workforce framework for community health workers: a model for advancing the profession. American Journal 
of Public Health. 2019;109(2):320-7.

https://doi.org/10.2105/ajph.2018.304737

21. Kallio H, Voutilainen A, Viinamäki L, Kangasniemi M. In-service training to enhance the competence of health and social care professionals: A document analysis of web-based training reports. Nurse Education Today. 2020;92:1-7. https://doi.org/10.1016/j.nedt.2020.104493

22. Tabbush V. Overview of preparing community-based organizations for successful health care partnerships [Internet]. Long Beach, California: The scan foundation; 2012 Aug [updated 2012 Aug 21; cited 2020 Sep 14]. Available from:

https://www.thescanfoundation.org/publications/overview -of-preparing-community-based-organizations-for-successful -health-care-partnerships/

23. Maryland department of health. Maryland Community Health Worker Core Competencies [Internet]. Baltimore: Maryland Department of Health; 2019 [cited 2020 Apr 7]. Available from: https://health.maryland.gov/pophealth/Community-Health -Workers/Pages/Certification-Program.aspx

24. South J, Raine G, White J. Community health champions: evidence review [Internet]. Leeds, UK: Leeds Metropolitan University; 2010 Sep [cited 2020 Aug 4]. Available from: https://core.ac.uk/display/373835551?source=2

25. NHS England and NHS Improvement. The matron's handbook [Internet]. London: NHS England; 2020 Jan [cited 2020 Aug 4]. Available from: https://www.england.nhs.uk/mat-transformation/matrons -handbook/

26. Nummela O, Juujärvi S, Sinervo T. Competence needs of integrated care in the transition of health care and social services in Finland. International Journal of Care Coordination. 2019; 22(1):36-45. https://doi.org/10.1177/2053434519828302

27. Creswell J, Poth CN. Qualitative inquiry and research design: choosing among five approaches. 4 th ed. Thousand Oaks, CA: SAGE; 2017. 459 p.

28. Skulmoski GJ, Hartman FT, Krahn J. The Delphi method for graduate research. Journal of Information Technology Education: Research. 2007;6(1):1-21. https://doi.org/10.28945/199

29. Lynn M. Determination and quantification of content validity. Nursing Research. 1986;35(6):382-5. https://doi.org/10.1097/00006199-198611000-00017

30. Willis A, Reed E, Pratt-Chapman M, Kapp H, Hatcher E, Vaitones $\mathrm{V}$, et al. Development of a framework for patient navigation: delineating roles across navigator types. Journal of Oncology Navigation \& Survivorship [Internet]. 2013 Dec [cited 2021 Jan 4]; 4(6). Available from:

https://www.jons-online.com/issues/2013/december-2013vol-4-no-6/1249-development-of-a-framework-for-patient- navigation-delineating-roles-across-navigator-types

31. Canadian Interprofessional Health Collaborative. A national interprofessional competency framework. The collaborative. Vancouver: Her Majesty the Queen in Right of Canada; 2010. $32 \mathrm{p}$.

32. Jolanki O, Tynkkynen LK, Sinervo T. Professionals' views on integrated care. Journal of Integrated Care. 2017;25(4):247-55. https://doi.org/10.1108/JICA-06-2017-0018

33. Begun JW, White KR, Mosser G. Interprofessional care teams: the role of the healthcare administrator. Journal of Interprofessional Care. 2011;25(2):119-23. https://doi.org/10.3109/13561820.2010.504135

34. Polley MJ, Fleming J, Anfilogoff T, Carpenter A. Making sense of social prescribing [Internet]. London: University of Westminister; 2017 Aug [cited 2020 Nov 21]. Available form: https://westminsterresearch.westminster.ac.uk/item/q1v77 /making-sense-of-social-prescribing

35. Leveaux C, Patel SJR, Culpan J, Macey M, Dize C, Camp T. Safer passage: how care navigators help improve mental health services [Internet]. London: 2012 Mar [updated 2012 Mar 6; cited 2020 Nov 19]. Available from: https://www.hsj.co.uk/partner-innovation/safer-passagehow-care-navigators-help-improve-mental-health-services/ 5041420.article

36. Bernstein A, Harrison KL, Dulaney S, Merrilees J, Bowhay A, Heunis J, et al. The role of care navigators working with people with dementia and their caregivers. Journal of Alzheimer's Disease. 2019;71(1):45-55. https://doi.org/10.3233/JAD-180957

37. Kangasniemi M, Karki S, Voutilainen A, Saarnio R, Viinamäki L, Häggman-Laitila A. The value that social workers' competencies add to health care: an integrative review. Health \& Social Care in the Community. 2020;00:1-12.

https://doi.org/10.1111/hsc.13266

38. Schofield R, Chircop A, Baker C, Dietrich Leurer M, Duncan S, Wotton D. Entry-to-practice public health nursing competencies: a Delphi method and knowledge translation strategy. Nurse Education Today. 2018;65:102-7. https://doi.org/10.1016/j.nedt.2018.03.001

39. South J, Woodall J, Kinsella K, White J. Community health champions and older people: a review of the Evidence [Internet]. Leeds, UK: Leeds Metropolitan University; 2012 Feb [cited 2021 Mar 10]. Available form: https://eprints.leedsbeckett.ac.uk/id/eprint/7371/

40. Blake H, Chambers D. Supporting nurse health champions: developing a 'new generation' of health improvement facilitators. Health Education Journal. 2012;71(2):205-10. https://doi.org/10.1177/0017896910396767 